\title{
Effect of Surfactant Properties on the Performance of Forward Osmosis Membrane Process
}

\author{
Kaiwit Ruengruehan', Seoktae Kang ${ }^{2}$, Nirawan Sanphoti ${ }^{3}$, Sutha Khaodhiar ${ }^{1 *}$ \\ 1 Department of Environmental Engineering, Faculty of Engineering, Chulalongkorn University Phayathai Rd., \\ Wangmai Pratumwan, Bangkok 10330, Thailand \\ 2 Department of Civil and Environmental Engineering, KAIST, Daejeon, 34141, Republic of Korea \\ ${ }^{3}$ Department of Community Health Faculty of Public Health, Kasetsart University, Chalermphrakiat Sakon \\ Nakhon Province Campus, Thailand \\ * Corresponding author's e-mail: sutha.k@chula.ac.th
}

\begin{abstract}
Wastewater treatments such as forward osmosis (FO) can be widely applied to separate or the reject substances from secondary treated effluents. Experimental studies have investigated the influence of membrane fouling and operating conditions. The performance of FO is affected by membrane fouling characteristics, composition of the feed solution and operating conditions. The experiments were performed using an osmotic membrane (FO-4040) to investigate the influences of operating conditions on water flux and reverse salt selectivity. The surfactant content, cross-flow velocity, and $\mathrm{pH}$ of the feed solution were systematically investigated for their effects on FO performance. The results showed that higher cross-flow velocities, increase of the $\mathrm{pH}$ of the feed solution, and adding surfactant into the feed solution yielded higher water fluxes. Reverse salt selectivity also increased after adding a surfactant to the feed solution but showed no significant increase at higher surfactant concentrations.
\end{abstract}

Keywords: omotically-membrane process; anionic surfactant; nonionic surfactant

\section{INTRODUCTION}

Forward osmotic (FO) membrane processes utilize the differences in solution concentration to generate an osmotic pressure gradient as the driving force. Diffusion in water molecules continually occurs across a semipermeable membrane from a less concentrated feed solution to a highly concentrated draw solution (She et al., 2012). The semipermeable membrane allows the water molecules and a small amount of salt to pass through, while most solute molecules and particulates are rejected (Mi et al., 2008). The advantages of the forward osmosis membrane process are that it can be used at low or zero hydraulic pressure, with high rejection in a wide range of pollutants. Forward osmosis can also be widely applied in many fields, such as water treatment, wastewater treatment, water reuse, brackish groundwater and seawater desalination (Mi et al., 2008; Cath et al., 2006; Yuan et al., 2010). As with other separation processes, many factors hinder the performance of forward osmosis, including solution properties, membrane properties, concentration polarization, and especially membrane fouling (Cath et al., 2006; Klaysom et al., 2013). Municipal wastewater contains a variety of organic and inorganic substances, and particulates from domestic sources include some toxic elements (Lutchmiah et al., 2014). Several studies found that the accumulation and interactions between the properties of the membrane and the properties of the foulant are the main causes of flux decline (Lee et al., 2005). Membrane fouling occurs due to the accumulation of colloidal particles on the osmotic membrane that generate cake enhanced osmotic pressure (CEOP) close to the membrane surface, resulting in flux decline in the forward osmosis process (Boo et al.,2012; Zhao et al., 2012; Valladares et al., 2011). 
Surfactant substances are widely used in many domestic processes; most are applied as detergents for washing and cleaning in daily life. After use, the residual surfactant molecules are normally discharged to the environmental system as domestic wastewater. The problems arising due to surfactant fouling are observed when membrane separation is applied for wastewater treatment (Kaya et al., 2006). Yang and his colleagues (Yang et al., 2005) reported that the relative flux of anionic surfactant decreased gradually in the cross-flow velocity of ultrafiltration (UF), and the adsorption and accumulation of surfactant molecules at the membrane surface induced greater diffusion of water molecules due to the membrane surface, becoming less hydrophobic with a negatively charged anionic surfactant (Kaya et al., 2006). In the case of non-ionic surfactant ultrafiltration, interaction with both negatively charged and neutral surfaces results in the adsorption that affects the membrane properties; however, the basic function of diffusion in water molecules occurs due to the interactions of hydrophobic or hydrophilic activity on neutral surfaces (Yang et al., 2005; Zhao et al., 2015; Kertész et al., 2008). Adsorption and the accumulation of surfactant on the membrane surface reduce the performance of separation (Childress and Deshmukh, 1998), while the physio-chemical properties such as the $\mathrm{pH}$ of the feed solution, cross-flow velocity and increase of the surfactant concentration are the main factors that affect flux decline of ultrafiltration (Paria and Khilar, 2004; Devia et al., 2015; Shibuya et al., 2015). However, few studies have investigated the effect of surfactant properties in combination with operating conditions $(\mathrm{pH}$ of feed solution, cross-flow velocity, and increase of surfactant concentration) in the forward osmosis process. Therefore, the effects of sodium dodecyl sulfate (SDS) as an anionic surfactant and nonylphenol ethoxylate (NP-40) were examined on an osmotic membrane under the conditions of forward osmosis. Water flux $\left(\mathrm{J}_{\mathrm{w}}\right)$ and reversal salt selectivity $\left(\mathrm{J}_{\mathrm{w}} / \mathrm{J}_{\mathrm{s}}\right)$ were also investigated on the osmotic membrane under various operating conditions and surfactant concentrations.

\section{MATERIALS AND METHODS}

\section{Feed solution chemistry}

Sodium dodecyl sulfate (SDS) and Tergitol $^{\mathrm{TM}}$ solution (NP-40) were selected as the representatives of an anionic and non-ionic surfactant, respectively. Sodium dodecyl sulfate (SDS) was purchased from Ajax Finechem Pty Ltd. with a molecular weight of $288.38 \mathrm{~g} / \mathrm{mol}$ $\left(\mathrm{NaC}_{12} \mathrm{H}_{25} \mathrm{SO}_{4}\right)$. The critical micelle concentration (CMC) of sodium dodecyl sulfate (SDS) is $8.2 \mathrm{mM}\left(25^{\circ} \mathrm{C}\right)$ (Mukerjee and Mysels, 1971). Tergitol ${ }^{\mathrm{TM}}$ solution (NP-40) was purchased from Sigma-Aldrich (USA) with critical micelle concentration (CMC) of $232.0 \mathrm{mg} / \mathrm{L}\left(25^{\circ} \mathrm{C}\right)$. The feed solution $\mathrm{pH}$ was adjusted by $0.02 \mathrm{~N} \mathrm{NaOH}$ and/or $0.02 \mathrm{~N} \mathrm{HCl}$

\section{Osmotic membrane}

High water flux membrane (FO-4040) used in this research was provided by Toray Korea (South Korea). Before starting the experiment, the membrane was soaked in de-ionized water for over $24 \mathrm{~h}$ (at $4.0^{\circ} \mathrm{C}$ ). The osmotic membrane was cut according to the size of the membrane cell (length, width, and channel height of $2.6 \mathrm{~cm}, 7.7 \mathrm{~cm}$, and $0.3 \mathrm{~cm}$, respectively) and then carefully placed between the two chambers of the membrane unit to separate the feed and draw solutions. The effective area of the osmotic membrane was $20.00 \mathrm{~cm}^{2}$.

\section{Forward osmosis operation}

The FO experimental setup consisted of a bench-scale flat sheet cross-flow membrane FO system. Schematic drawings of the FO lab-scale cross-flow system can be found in our previous publication (Ruengruehan et al., 2014). The FO system consisted of a cross-flow membrane cell with the internal dimensions of $7.7 \mathrm{~cm}$ length, 2.6 $\mathrm{cm}$ width and $0.3 \mathrm{~cm}$ height, two peristaltic pumps (BT100M/YZ1515x) to circulate the draw solution (DS) and feed solution (FS) in corresponding closed loops, solution reservoir tanks and a weighing balance (AND GF-4000, Japan) to continuously record the variation in the DS weight for water flux computation. The initial volumes of feed and draw solution were $2.0 \mathrm{~L}$, and $2.0 \mathrm{~L}$, respectively. The operation time for each experiment was $8.0 \mathrm{~h}$, with the temperature controlled at $25.0 \pm 0.5^{\circ} \mathrm{C}$ for all experiments. The baseline experiments were also conducted to quantify the flux decline due to a decrease in the osmotic driving force during the fouling experiments, with the draw solution continuously diluted by the permeate water. The baseline experiments followed the same protocol as for the fouling experiments 
except, that no foulant was added to the feed solution. The baseline of each experiment was demonstrated for 60 minutes minus any fouling in the feed solution. Then, after the data stabilized, the weighing balance began counting automatically.

\section{RESULTS AND DISCUSSION}

\section{Impact of the operating condition in pristine membrane}

In order to investigate the effect of the draw solution concentration on the FO performance, the experiments were conducted under different concentrations of $0.5,1.0,2.0$ and $3.0 \mathrm{M} \mathrm{NaCl}$. The cross-flow velocity of both feed and draw solutions was fixed at $7.0 \mathrm{~cm} / \mathrm{s}$. the results of these experiments are summarized in Table 1 and show that the water flux and salt flux significantly increased with draw solution concentration due to an increase in the osmotic pressure gradient. When the osmotic pressure gradient of a forward osmosis process is elevated, the movement of water molecules and diffusion of salt molecules also increase (Hoek and Elimelech, 2003). The effect of the cross-flow velocity on the FO process was investigated. The results showed that the crossflow velocities of both the feed and draw solutions were similar $(0.5,0.9,7.0$, and $10.5 \mathrm{~cm} / \mathrm{s})$. The concentration of feed solution was fixed at $10.0 \mathrm{mM} \mathrm{NaCl}$, and the draw solution concentration was $1.0 \mathrm{M} \mathrm{NaCl}$ for all conditions. The influence of cross-flow velocity on water flux in the
FO process is shown in Table 2. The water flux of the FO process was highest at a velocity of 10.5 $\mathrm{cm} / \mathrm{s}$, followed by $7.0 \mathrm{~cm} / \mathrm{s}, 0.9 \mathrm{~cm} / \mathrm{s}$ and $0.5 \mathrm{~cm} / \mathrm{s}$. An increase in the cross-flow velocity mitigated the flux decline in the FO process. The results of this experiment concurred with several research groups (Yuan et al., 2010; Lee et al., 2005; She et al., 2008; Cornelissen et al., 2008). The water flux increased at higher cross-flow velocity of the process but the increase was less marked at relatively high cross-flow values as presented in Table 2 . The water flux of the FO process was affected due to the change in the osmotic pressure gradient with increasing draw solution but an increase in the cross-flow velocity of the feed solution did not have a significant effect on the diffusion of water molecules and did not drastically alter the properties of the membrane. The results of this study may be related to the influence of internal concentration polarization (ICP) in the FO process (Yuan et al., 2010; Boo et al., 2012; Zhao et al., 2012). An increase in the cross-flow velocity reduced the accumulation of salt molecules on the membrane surface. An increase in the draw solution concentration played a major role regarding the ICP phenomenon of the FO process. In order to investigate the influence of the $\mathrm{pH}$ of the feed solution, the condition of the feed solution was carefully adjusted utilizing $0.02 \mathrm{~N} \mathrm{HCl}$ and $0.02 \mathrm{~N}$ $\mathrm{NaOH}$. The cross-flow velocity of both feed and draw solutions was fixed at $7.0 \mathrm{~cm} / \mathrm{s}$ and $1.0 \mathrm{M}$ $\mathrm{NaCl}$ of draw solution. The effect of the $\mathrm{pH}$ of the feed solution is shown in Table 3. The results showed that the water flux increased when the $\mathrm{pH}$

Table 1. Data for FO processes run under different draw concentrations

\begin{tabular}{|c|c|c|c|c|c|c|}
\hline \multicolumn{2}{|c|}{ Active Layer } & \multicolumn{2}{|c|}{ Supporting Layer } & \multirow{2}{*}{$\begin{array}{l}\text { Water Flux } \\
\quad \text { (LHM) }\end{array}$} & \multirow{2}{*}{$\begin{array}{c}\text { Salt Flux } \\
\left(\mathrm{mmole} / \mathrm{m}^{2}-\mathrm{h}\right)\end{array}$} & \multirow{2}{*}{$\begin{array}{c}\text { Reverse Salt } \\
\text { Selectivity (L/mole) }\end{array}$} \\
\hline $\begin{array}{l}\mathrm{NaCl} \\
(\mathrm{M})\end{array}$ & $\begin{array}{c}\pi \\
(\mathrm{atm})\end{array}$ & $\begin{array}{l}\mathrm{NaCl} \\
(\mathrm{M})\end{array}$ & $\begin{array}{c}\pi \\
(\mathrm{atm})\end{array}$ & & & \\
\hline 0.01 & 0.5 & 0.5 & 24.5 & 13.5 & 243.3 & 56.0 \\
\hline 0.01 & 0.5 & 1.0 & 48.9 & 24.7 & 454.5 & 50.0 \\
\hline 0.01 & 0.5 & 2.0 & 97.8 & 33.7 & 656.5 & 52.0 \\
\hline 0.01 & 0.5 & 3.0 & 146.7 & 44.5 & 790.8 & 56.0 \\
\hline
\end{tabular}

Table 2. Data for FO processes run under different cross-flow velocities $(\mathrm{cm} / \mathrm{s})$

\begin{tabular}{|c|c|c|c|c|c|c|c|}
\hline \multirow{2}{*}{$\begin{array}{l}\text { Cross-flow } \\
\text { velocity } \\
(\mathrm{cm} / \mathrm{s})\end{array}$} & \multicolumn{2}{|c|}{ Active Layer } & \multicolumn{2}{|c|}{ Supporting Layer } & \multirow{2}{*}{$\begin{array}{l}\text { Water Flux } \\
\text { (LHM) }\end{array}$} & \multirow{2}{*}{$\begin{array}{c}\text { Salt Flux } \\
\left(\mathrm{mmole} / \mathrm{m}^{2}-\mathrm{h}\right)\end{array}$} & \multirow{2}{*}{$\begin{array}{c}\text { Reverse Salt } \\
\text { Selectivity (L/mole) }\end{array}$} \\
\hline & $\begin{array}{c}\mathrm{NaCl} \\
(\mathrm{M})\end{array}$ & $\begin{array}{c}\pi \\
\text { (atm) }\end{array}$ & $\begin{array}{c}\mathrm{NaCl} \\
(\mathrm{M})\end{array}$ & $\begin{array}{c}\pi \\
(\mathrm{atm}) \\
\end{array}$ & & & \\
\hline 0.5 & 0.01 & 0.48 & 1.0 & 48.9 & 13.4 & 256.9 & 52.0 \\
\hline 0.9 & 0.01 & 0.48 & 1.0 & 48.9 & 19.2 & 366.0 & 53.0 \\
\hline 7.0 & 0.01 & 0.48 & 1.0 & 48.9 & 23.6 & 463.8 & 51.0 \\
\hline 10.5 & 0.01 & 0.48 & 1.0 & 48.9 & 26.4 & 508.0 & 52.0 \\
\hline
\end{tabular}


Table 3. Data for FO processes run under different $\mathrm{pH}$ feed solutions

\begin{tabular}{|c|c|c|c|c|c|c|c|}
\hline \multirow{2}{*}{$\begin{array}{l}\mathrm{pH} \text { in the feed } \\
\text { solution }\end{array}$} & \multicolumn{2}{|c|}{ Active Layer } & \multicolumn{2}{|c|}{ Supporting Layer } & \multirow{2}{*}{$\begin{array}{l}\text { Water Flux } \\
\quad \text { (LHM) }\end{array}$} & \multirow{2}{*}{$\begin{array}{c}\text { Salt Flux } \\
\left(\mathrm{mmole} / \mathrm{m}^{2}-\mathrm{h}\right)\end{array}$} & \multirow{2}{*}{$\begin{array}{c}\text { Reverse Salt } \\
\text { Selectivity (L/mole) }\end{array}$} \\
\hline & $\begin{array}{c}\mathrm{NaCl} \\
(\mathrm{M})\end{array}$ & $\begin{array}{c}\pi \\
(\mathrm{atm})\end{array}$ & $\begin{array}{l}\mathrm{NaCl} \\
(\mathrm{M})\end{array}$ & $\begin{array}{c}\pi \\
(\mathrm{atm})\end{array}$ & & & \\
\hline 4.0 & 0.01 & 0.48 & 1.0 & 48.9 & 20.5 & 565.0 & 31.0 \\
\hline 7.0 & 0.01 & 0.48 & 1.0 & 48.9 & 23.8 & 463.8 & 51.0 \\
\hline 10.0 & 0.01 & 0.48 & 1.0 & 48.9 & 32.7 & 460.5 & 71.0 \\
\hline
\end{tabular}

value changed from low to high. Remarkably, the diffusion of water molecules occurred only slightly when the $\mathrm{pH}$ was adjusted from 4.0 to 7.0. However, there was a significant increase in the diffusion of water molecules when the $\mathrm{pH}$ was adjusted from 7.0 to 10.0. This may be due to the change in the membrane properties as a result of a negatively charged osmotic membrane under various $\mathrm{pH}$ conditions (Childress and Deshmukh, 1998). The increase in water flux was promoted by a more negatively charged membrane surface. On the other hand, the diffusion was retarded when the membrane surface was less negatively charged.

\section{Effect of cross-flow velocity on FO performance}

In order to investigate the influence of crossflow velocity on FO performance in the presence of SDS of NP-40 were added. The experiments were conducted at different cross-flow velocities of $0.5,0.9,7.0$, and $10.5 \mathrm{~cm} / \mathrm{s}$. From the graphical plots in Figure 1, it can be clearly observed that the water flux slightly increased when the cross-flow velocity of the FO process was carefully adjusted from 0.5 to $10.5 \mathrm{~cm} / \mathrm{s}$. At crossflow velocities higher than $7.0 \mathrm{~cm} / \mathrm{s}$, the water flux increased. It was highest in the case of the feed solution containing SDS, followed by NP40 , and the pristine membrane. The results suggested that the properties of the membrane were modified after covering with surfactant, resulting in an increase in water flux by increasing the hydrophilic nature of the surface. The contact angles were measured to investigate the hydrophilicity of the surfactant-absorbed membrane surfaces. In our experiment, the contact angle of a pristine membrane before surfactant application in the FO process was 46 degrees; however, it was not possible to measure the contact angle of the surfactant-fouled membrane since the dropping liquid (water solution) quickly flattened on the fouled membrane that was extremely hydrophilic.
Furthermore, the diffusion of water and salt molecules across the osmotic membrane as reported in reverse salt selectivity was also continually investigated during the FO operation. In the case of the pristine membrane, an increase of crossflow velocity significantly promoted the diffusion of water molecules crossing the membrane surface (Figure 2). These results were similar to previous publications (Zhao et al., 2015; Nguyen et al., 2015). On the other hand, the reverse salt selectivity flux significantly increased when the cross-flow velocity of the FO process was adjusted from 0.5 to $10.5 \mathrm{~cm} / \mathrm{s}$ and surfactant was added to the feed solution. As shown by the results of contact angle measurement, surfactant fouling changed the properties of the membrane surface, and membrane deformation resulted in greater diffusion of water molecules. This phenomenon occurred because the higher cross-flow velocity decreased the boundary layer thickness (Zhao et al., 2015; Philip et al., 2010) and changed the membrane surface properties after the adsorption of surfactant molecules.

\section{Effect of the $\mathrm{pH}$ of the feed solution on FO performance}

In order to investigate the effect of the $\mathrm{pH}$ of the feed solution on FO performance, the $\mathrm{pH}$ of the feed solution was varied from 4.0 to 10.0 , and the total ionic strength in the feed solution was fixed at $10 \mathrm{mM} \mathrm{NaCl}$. Two types of surfactant were used in this experiment $(2.3 \mathrm{~g} / \mathrm{L}$ of SDS and $0.2 \mathrm{~g} / \mathrm{L}$ of NP-40). The initial volumes of draw solution and feed solution were both $2.0 \mathrm{~L}$, and cross-flow velocity was fixed at $7.0 \mathrm{~cm} / \mathrm{s}$. Figure 3 illustrates the effect of different $\mathrm{pH}$ levels in the feed solution on the FO performance. The results indicated that the water flux of the FO process increased after the $\mathrm{pH}$ of the feed solution was elevated from 4.0 to 10.0 in the presence of surfactant, especially, anionic surfactant (SDS). This revealed that the effect of $\mathrm{pH}$ of the feed solution generated 


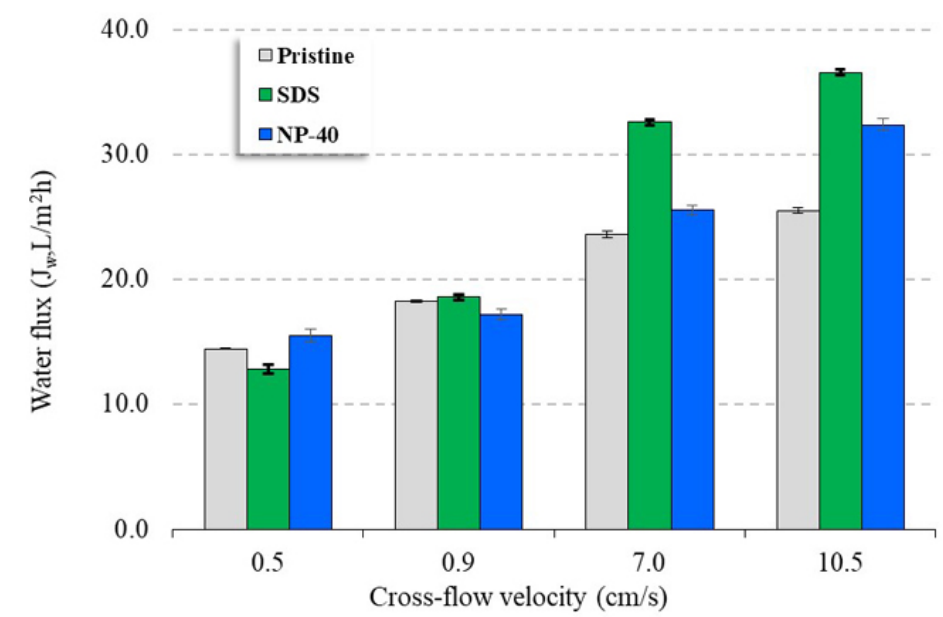

Figure 1. Effect of cross-flow velocity and additive of surfactant on the FO performance. The velocity of both feed and draw solutions was varied $(0.5,0.9,7.0$, and $10.5 \mathrm{~cm} / \mathrm{s})$. The temperature was controlled at $25.0^{\circ} \mathrm{C}$. The $\mathrm{pH}$ of both feed and draw solutions was fixed at 7.0

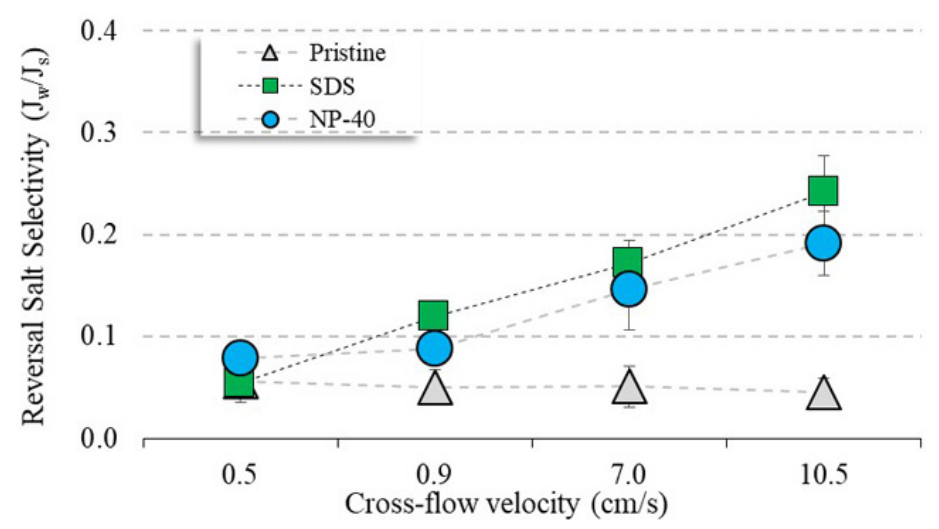

Figure 2. Effect of cross-flow velocity on the FO performance. The cross-flow velocity of both feed and draw solutions was varied $(0.5,0.9,7.0$, and $10.5 \mathrm{~cm} / \mathrm{s})$. The temperature was controlled at $25.0^{\circ} \mathrm{C}$. The $\mathrm{pH}$ of both feed and draw solutions was fixed at 7.0

interactions between the surfactant moleculesmembrane surfaces. In the absence of surfactants, the membrane surfaces were positively charged at low $\mathrm{pH}$ and more negatively charged (Childress and Deshmukh, 1998), and interactions between the surfactant molecules and membrane properties promoted the diffusion of water molecules, as explained by the contact angle measurement. Therefore, the water flux increased due to more negatively charged ( $\mathrm{pH} 4.0$ to 10.0) and changed properties of the membrane surfaces.

Meanwhile, the water flux significantly increased when the feed solution $\mathrm{pH}$ was raised from 4.0 to 10.0. Conversely, the diffusion of salt molecules did not follow the flux trend. In order to understand this phenomenon, the relationship between water flux and salt flux was reported as reverse salt selectivity. As plotted in Figure 4, reverse salt selectivity significantly increased after adding surfactants into the feed solution. This occurred because of the change of membrane properties due to the negative charge, and the interactions between the surfactant molecules and membrane surface. As mentioned above, the adsorbed surfactant on the membrane surface promoted the diffusion of water molecules, and the contact angle measurement indicated the passage of water molecules. On the other hand, the covering of surfactant on the surface of the membrane increased the diffusion resistance of the salt molecules (Zhao et al., 2015; Kertész et al., 2008; Childress and Deshmukh, 1998), while the adsorption of the surfactant significantly increased the reverse salt selectivity at high $\mathrm{pH}$. 


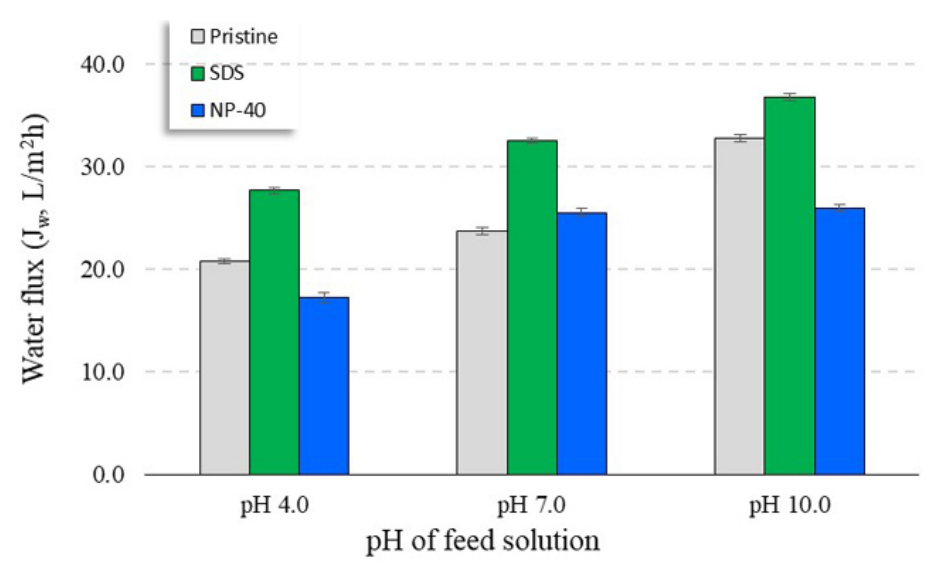

Figure 3. Effect of $\mathrm{pH}$ in feed solution on the FO performance. $\mathrm{pH}$ in feed solutions was varied (4.0, 7.0, and 10.0). The temperature was controlled at $25.0^{\circ} \mathrm{C}$. The $\mathrm{pH}$ of both feed and draw solutions was fixed at 7.0

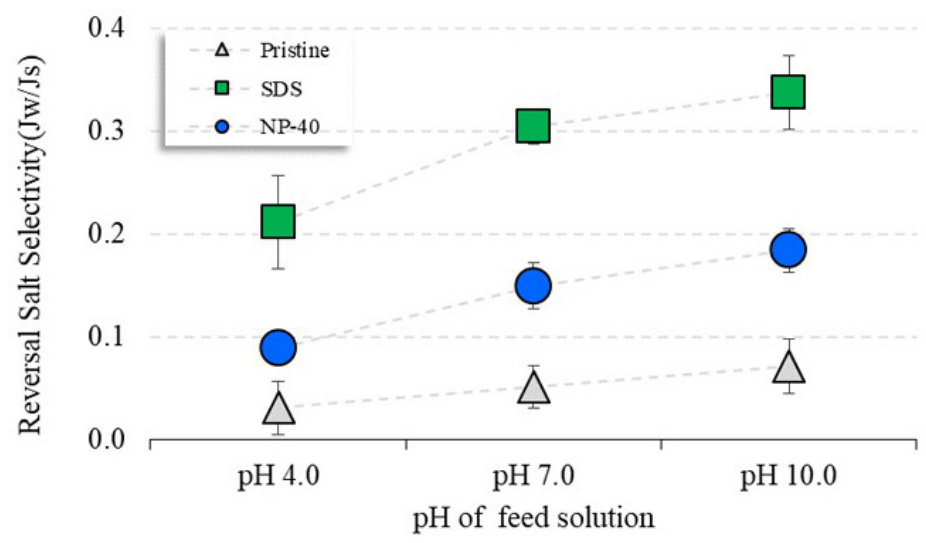

Figure 4. Reverse salt selectivity under various $\mathrm{pH}$ in presence of surfactant. The $\mathrm{pH}$ of feed solution was varied $\left(4.0,7.0\right.$, and 10.0). The temperature was controlled at $25.0^{\circ} \mathrm{C}$. The $\mathrm{pH}$ of draw solution was fixed at 7.0

\section{Effect of surfactant concentration on FO performance}

In order to investigate the effect of increased concentration of anionic and non-ionic surfactant on the FO performance, the concentrations of SDS and NP-40 surfactants were varied from 0 to $2.4 \mathrm{~g} / \mathrm{L}$ and from 0 to $232.0 \mathrm{mg} / \mathrm{L}$, respectively. The cross-flow velocity was fixed at 7.0 $\mathrm{cm} / \mathrm{s}$ and the $\mathrm{pH}$ of the feed solution was 7.0. Figure 5 presents the change of permeate flux at various surfactant concentrations. In the case of SDS, the water flux increased after adding the SDS surfactant into the feed solution. The water flux was highest at $2.4 \mathrm{~g} / \mathrm{L}$ of SDS, followed by $1.2,0.2$ and $0 \mathrm{~g} / \mathrm{L}$. The averages of water flux were $32.6,29.8,29.0$, and $23.8 \mathrm{~L} /$ $\mathrm{m}^{2}$-h, respectively. In the presence of feed solution containing NP-40 surfactant, the averages of permeate flux were 24.4, 25.2, 25.6, and 26.5 $\mathrm{L} / \mathrm{m}^{2}$-h for NP-40, respectively. The trends of permeate flux of both SDS and NP-40 surfactant increased at higher concentration but the permeate flux did not show any further significant increase when the concentration was increased to double the amount.

Figure 6 illustrates reverse salt selectivity under different concentration conditions of the surfactant in the feed solution. The trend of reverse salt selectivity increased when the concentration of both surfactants was adjusted from 0 to $2.4 \mathrm{~g} / \mathrm{L}$ of SDS, and 0 to $232.0 \mathrm{mg} / \mathrm{L}$ of NP-40. The reverse salt selectivity significantly increased at the beginning of the experiment, but thereafter it was not clearly distinguished after increasing the concentration of the surfactant. This indicated that the effect of covering due to adsorption of surfactant on the membrane surface occurred rapidly, and although the concentration increased, this did not result in any great change of reverse salt selectivity. 
a)

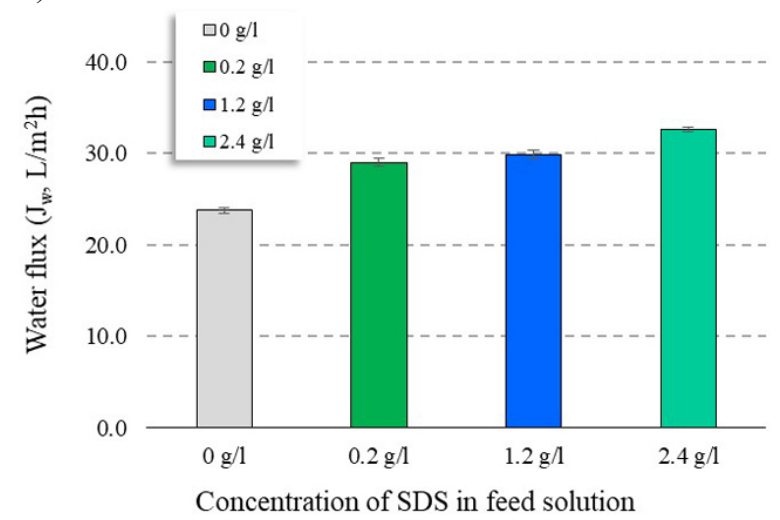

b)

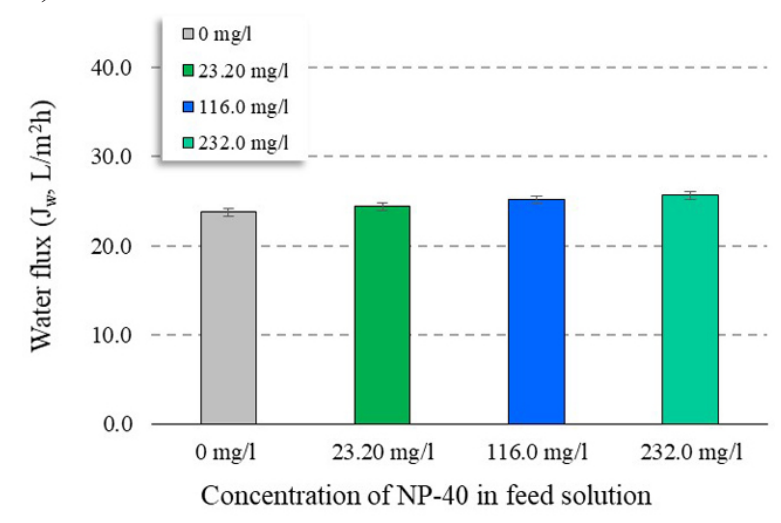

Figure 5. Water flux of FO processes under various surfactant concentrations: a) SDS surfactant, b) NP-40 surfactant. The cross-flow velocity of both feed and draw solutions was fixed at $7.0 \mathrm{~cm} / \mathrm{s}$. The pH of feed solution was fixed at 7.0. The temperature was controlled at $25.0{ }^{\circ} \mathrm{C}$. The $\mathrm{pH}$ of draw solution was fixed at 7.0

a)

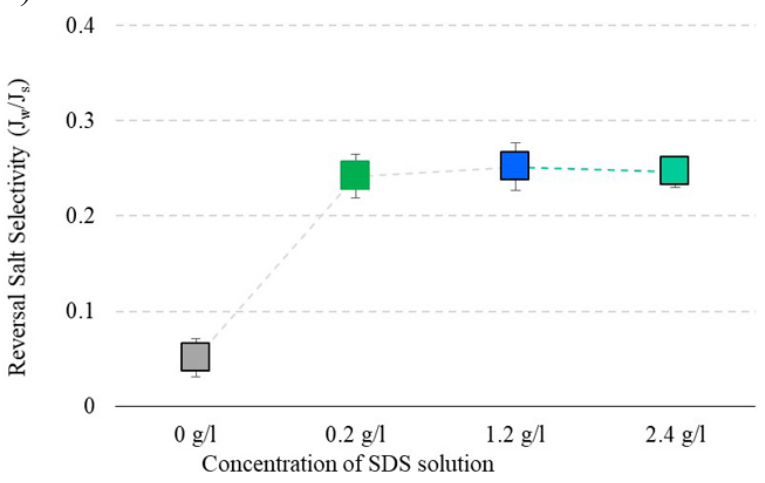

b)

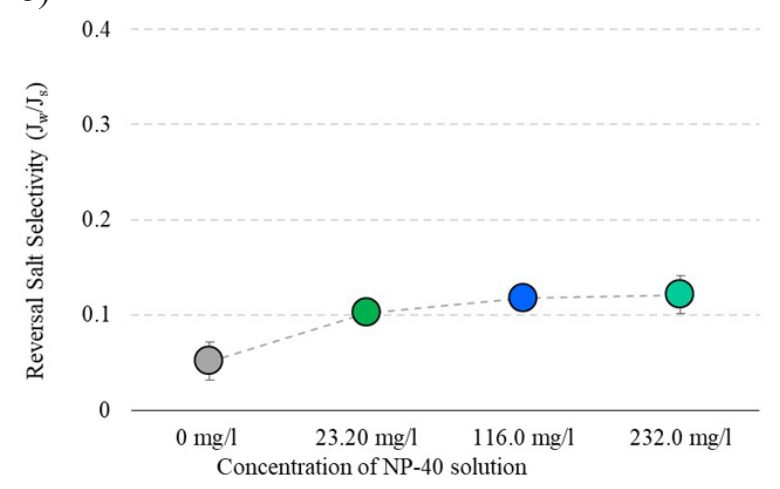

Figure 6. Reverse salt selectivity under various surfactant concentrations: a) SDS surfactant, b) NP-40 surfactant. The cross-flow velocity of both feed and draw solutions was fixed at $7.0 \mathrm{~cm} / \mathrm{s}$. The $\mathrm{pH}$ of feed solution was fixed at 7.0. The temperature was controlled at $25.0{ }^{\circ} \mathrm{C}$. The $\mathrm{pH}$ of draw solution was fixed at 7.0

\section{CONCLUSIONS}

The influence of feed solution containing surfactant molecules on the performance of the FO process was investigated under three different operating conditions (cross-flow velocity, $\mathrm{pH}$ of the feed solution and surfactant concentration). Flat sheet osmotic membranes were used in this study (FO-4040). In the presence of a surfactant, the results revealed that water flux increased along with the osmotic pressure gradient and $\mathrm{pH}$ of the feed solution. The change of membrane properties due to covering by the surfactant increased the diffusion of the water molecules. In the case of cross-flow velocity, water flux was only slightly increased, even though the cross-flow velocity of the FO system doubled. In addition, the reverse salt selectivity of both osmotic pressure gradient and cross-flow velocity did not show any significant change when the condition was adjusted.
By contrast, an increase in reverse salt selectivity was clearly observed when the $\mathrm{pH}$ of the feed solution was adjusted from 4.0 to 10.0.

\section{Acknowledgment}

The research was supported by THE $90^{\mathrm{TH}}$ Anniversary of Chulalongkorn University Scholarship.

\section{REFERENCES}

1. Boo C., Lee S., Elimelech M., Meng Z., Hong S. 2012. Colloidal fouling in forward osmosis: Role of reverse salt diffusion. Journal of Membrane Science, $390,277-284$

2. Cath T.Y., Childress A.E., Elimelech M. 2006. Forward osmosis: Principles, applications, and recent developments. Journal of Membrane Science, 281(1-2), 70-87. 
3. Childress A.E., Deshmukh S.S. 1998. Effect of humic substances and anionic surfactant on the surface charge and performance of reverse osmosis membrane. Desalination, 118, 167-174.

4. Cornelissen E.R., Harmsen D., de Korte K.F., Ruiken C.J., Qin J.J., Oo H., Wessels L.P. 2008. Membrane fouling and process performance of forward osmosis membranes on activated sludge. Journal of Membrane Science, 319, 158-168.

5. Devia Y.P., Imai T., Higuchi T., Kanno A., Yamamoto K., Sekine M., Le T.V. 2015. Potential of magnesium chloride for nutrient rejection in forward osmosis. Journal of Water Resource and Protection, 7(9), 11.

6. Hoek E.M.V., Elimelech M. 2003. Cake-Enhanced Concentration Polarization: A New Fouling Mechanism for Salt-Rejecting Membranes. Environmental Science \& Technology, 37(24), 5581-5588.

7. Kaya Y, Aydiner C., Barlas H., Keskinler B. 2006. Nanofiltration of single and mixture solutions containing anionics and nonionic surfactants below their critical micelle concentrations (CMCs). Journal Membrane Science, 282, 401-412.

8. Kertész S.Z., Lászlób Z.S., Horváth S.Z.H., Hodúr C. 2008. Analysis of nanofiltration parameters of removal of an anionic detergent. Desalination, 221, 303-311.

9. Klaysom C., Cath T.Y., Depuydt T., Vankelecom I.F.J. 2013. Forward and pressure retarded osmosis: potential solutions for global challenges in energy and water supply. Chemical Society Reviews. 42, 6959-6989.

10. Lee S., Cho J., Elimelech M. 2005. Combined influence of natural organic matter (NOM) and colloidal particles on nanofiltration membrane fouling. Journal of Membrane Science, 262(1-2), 27-41.

11. Lutchmiah K., Verliefde A.R., Roest K., Rietveld L.C., Cornelissen E.R. 2014. Forward osmosis for application in wastewater treatment: A review. Water Research, 58, 179-197.

12. Mi B., Elimelech M. 2008. Chemical and physical aspects of organic fouling of forward osmosis membranes. Journal of Membrane Science, 320(12), 292-302

13. Mukerjee P., Mysels K.J. 1971. Critical micelle concentrations of aqueous surfactant systems. U.S. National Bureau of Standards; for sale by the Supt. of Docs., U.S. Govt. Print. Off.

14. Nguyen N.T., Nguyen N.C., Chen S.S., Li C.W., Hsu H.T., Wu S.T. 2015. Innovation in draw solute for practical zero salt reverse in forward osmosis desalination. Industrial \& Engineering Chemistry Research. 54(23) 6067-6074.
15. Ruengruehan K., Kim H., Haiyen L.T., Lee W., Kang S. 2014. Fatty acids fouling on forward osmosis membrane: impact of $\mathrm{pH}$. Desalination and water treatment, 57(16), 7531-7537.

16. Paria S., Khilar K.C. 2004. A review on experimental studies of surfactant adsorption at the hydrophilic solid-water interface. Advances in Colloid and Interface Science, 110(3), 75-95.

17. Phillip W.A., Yong J.S., Elimelech M. 2010. Reverse draw solute permeation in forward osmosis: Modeling and experiments. Environmental Science \& Technology, 44(13), 5170-5176.

18. She Q. 2008. Effect of hydrodynamic conditions and feedwater composition on fouling of ultrafiltration and forward osmosis membranes by organic macromolecules. M.Eng. Thesis. School of Civil and Environmental Engineering, Nanyang Technological University, Singapore.

19. She Q., Jin X., Li Q., Chuyang Y.T. 2012. Relating reverse and forward solute diffusion to membrane fouling in osmotically driven membrane processes. Water Research, 46(7) 2478-2486.

20. Shibuya M., Yasukawa M., Takahashi T., Miyoshi T., Higa M., Matsuyama H. 2015. Effects of operating conditions and membrane structures on the performance of hollow fiber forward osmosis membranes in pressure assisted osmosis. Desalination, $365,381-388$.

21. Suh C., Lee S. 2013. Modeling reverse draw solute flux in forward osmosis with external concentration polarization in both sides of the draw and feed solution. Journal of Membrane Science, 427, 365-374.

22. Valladares L.R., Yangali-Quintanilla V., Li Z., Amy G. 2011. Rejection of micropollutants by clean and fouled forward osmosis membrane. Water Research, 45, 6737-44.

23. Yang J.S., Baek K., Yang J.W. 2005. Crossflow ultrafiltration of surfactant solutions. Desalination, 184(1-3), 385-394

24. Yuan X., Xiaoyu P., Chuyang Y.T., Shiang F., Shengzhe N. 2010. Effect of draw solution concentration and operating conditions on forward osmosis and pressure retarded osmosis performance in a spiral wound module. Journal of Membrane Science, 348(1-2), 298-309.

25. Zhao S., Zou L., Tang C.Y., Mulcahy D. 2012. Recent developments in forward osmosis: Opportunities and challenges. Journal of Membrane Science, 396, 1-21.

26. Zhao P., Gao B., Yue Q., Shon H.K. 2015. The performance of forward osmosis process in treating the surfactant wastewater: The rejection of surfactant, water flux and physical cleaning effectiveness. Chemical Engineering Journal, 281, 688-695. 